doi: https://doi.org/10.15407/dopovidi2019.03.025

UDC 512.544

\author{
L.A. Kurdachenko ${ }^{1}$, N.N. Semko ${ }^{2}$, I.Ya. Subbotin ${ }^{3}$ \\ ${ }^{1}$ Oles Honchar Dnipro National University \\ ${ }^{2}$ University of State Fiscal Service of Ukraine, Irpin \\ ${ }^{3}$ National University, Los Angeles, USA \\ E-mail: lkurdachenko@i.ua,dr.mykola.semko@gmail.com, isubboti@nu.edu
}

\title{
A generalization of the malnormal subgroups
}

Presented by Academician of the NAS of Ukraine A.M. Samoilenko

A subgroup $H$ of a group $G$ is called malonormal in $G$, if $H \cap H^{x}=\langle 1\rangle$ for every element $x \notin N_{G}(H)$. These subgroups are generalizations of malnormal subgroups. Every malnormal subgroup is malonormal, and every self-normalizing malonormal subgroup is malnormal. Furthermore, every normal subgroup is malonormal. In this paper we obtain a description of finite and certain infinite groups, whose subgroups are malonormal.

Keywords: malnormal subgroups, malonormal subgroups, Frobenius group, locally graded groups, generalized radical groups.

Let $G$ be a group. A subgroup $H$ of a group $G$ is called malnormal in $G$, if $H \cap H^{x}=\langle 1\rangle$ for every element $x \notin H$. In particular, every normal subgroup is malnormal.

The term "a malnormal subgroup" has been introduced by B. Baumslag [1].

Malnormal subgroups arise in finite groups as Frobenius complements in Frobenius groups. The Frobenius complements of Frobenius groups are described quite well (see, for example, [2, Chapter 10, Theorem 3.1]). In this connection, we note the following result:

If $G$ is a finite group and $H, K$ are malnormal subgroups of $G$, then there exists an element $g$ such that $H^{g} \leqslant K$ or $K^{g} \leqslant H$ (P. Flavell [3]).

The situation with malnormal subgroups in infinite groups much more complicated. The following result justifies this statement:

If $K$ and $L$ are non-trivial groups, then $K$ is malnormal in the free product $H * K$ [4, Proposition 2].

In [4], the role of malnormal subgroups in different classes of infinite groups was shown in various cases. As can be seen from the definition, malnormal subgroups are antagonists to normal subgroups: A normal subgroup $H$ of a group $G$ is malnormal in $G$ if and only if $H=\langle 1\rangle$ or $H=G$.

A similar situation holds with another antagonist to normal subgroups, namely with abnormal subgroups. Recall that a subgroup $H$ of a group $G$ is called abnormal if $x \in\left\langle H, H^{x}\right\rangle$ for each element $x \in G$. A normal subgroup $H$ of a group $G$ is abnormal in $G$ if and only if $H=G$.

(C) L.A. Kurdachenko, N.N. Semko, I.Ya. Subbotin, 2019 
Nevertheless, there are subgroups that are simultaneously a generalization of both abnormal and normal subgroups. Such are the pronormal subgroups. Recall that a subgroup $H$ of a group $G$ is called pronormal, if the subgroups $H$ and $H^{x}$ are conjugate in $\left\langle H, H^{x}\right\rangle$ for each element $x \in G$.

These types of subgroups and other types of subgroups associated with them are subjects of a vast array of articles. The results of these articles are reflected in survey [5].

We want to introduce a similar generalization of malnormal subgroups, namely, we want to introduce here the following class of subgroups containing both malnormal subgroups and normal subgroups.

A subgroup $H$ of a group $G$ is called malonormal in $G$, if $H \cap H^{x}=\langle 1\rangle$ for every element $x \notin N_{G}(H)$.

Thus, every malnormal subgroup is malonormal, and every self-normalizing malonormal subgroup is malnormal. Furthermore, every normal subgroup is malonormal.

In this paper, we considered the groups, whose all subgroups are malonormal. These class of groups includes the groups, whose subgroups are normal. Recall that groups, whose subgroups are normal, are called Dedekind groups. If $G$ is a Dedekind group, then either $G$ is Abelian or $G=Q$ $\times B \times S$, where $Q$ is a quaternion group, $B$ is an elementary Abelian 2-subgroup, $S$ is a periodic Abelian $p^{\prime}$-subgroup [6].

A special consideration is given to finite groups, whose subgroups are malonormal. Our first main result is the description of such groups.

Theorem A. Let $G$ be a finite group, whose subgroups are malonormal. Then $G$ is a group of one of the following types:

(i) $G$ is a Dedekind group;

(ii) $G=\langle v\rangle \lambda\langle u\rangle$, where $|v|=p^{k}, k \geqslant 3,|u|=p$ and $v^{u}=v$, where $s=1+p^{k-1}, p$ is a prime;

(iii) $G=(\langle c\rangle \times\langle v\rangle) \lambda\langle u\rangle$, where $|c|=|v|=|u|=p>2$ and $[v, u]=c$, $p$ is a prime;

(iv) $G=(\langle z\rangle \times\langle a\rangle) \lambda\langle u\rangle$, where $\left.|a|=|u|=p,|z|>p^{k}, k\right\rangle 1,[z, u]=1,[a, u]=c$, where $\langle c\rangle=\Omega_{1}(Z), p$ is a prime;

(v) $G=Q D,[Q, D]=\langle 1\rangle$, where $Q$ is a quaternion group of order $8, D$ is a dihedral group of order 8 and $Q \cap D=\zeta(Q)=\zeta(D)$;

(vi) $G=Q \lambda K$, where $Q$ is an elementary Abelian $q$-subgroup of order $q^{2}, q$ is a prime, $K$ is a cyclic $q^{\prime}$-subgroup, $2 \notin \Pi(K), K$ does not include a non-trivial cyclic $\langle y\rangle$-invariant subgroup for each $y \in K$;

(vii) $G=Q \lambda K$, where $|Q|=q$ is prime, $Q=C_{G}(Q), K$ is a cyclic subgroup of order dividing $q-1$.

Conversely, in any listed above group, each subgroup is malonormal.

The natural next stage is the consideration of infinite groups with this property. The situation with periodic groups is not very visible. A.Yu. Olshanskii [7] constructed the example of an infinite finitely generated $p$-group $O, p$ is a quite big prime, all of whose proper subgroups have order $p$. It is clear that every proper subgroup of this group is malnormal. Therefore, some additional restrictions were required.

A group $G$ is said to be locally graded if every non-trivial finitely generated subgroup of $G$ includes a proper subgroup of finite index.

This definition belongs to S.N. Chernikov [8].

We were able to obtain the following results. 
Theorem B. Let $G$ be an infinite periodic locally graded group, whose subgroups are malonormal. Then $G$ is a group of one of the following types:

(i) $G$ is a Dedekind group;

(ii) $G=(K \times\langle c\rangle) \lambda\langle b\rangle$, where $K=\left\langle a_{n} \mid a_{1}{ }^{p}=1, a_{n+1}{ }^{p}=a_{n}, n \in N\right\rangle$ is a quasicyclic $p$-subgroup, $c^{p}=b^{p}=1,[K, b]=\langle 1\rangle,[b, c]=a_{1}$, where $p$ is a prime.

Conversely, in every of these groups, each subgroup is malonormal.

For non-periodic locally graded groups, the situation is simpler.

Theorem C. Let $G$ be a locally graded group, whose subgroups are malonormal. If $G$ is non-periodic, then $G$ is Abelian.

Another restriction, which we used, connected to the generalized solvability.

A group $G$ is called a generalized radical if $G$ has an ascending series, whose factors are locally nilpotent or locally finite.

It is not hard to see that a generalized radical group has an ascending series of normal, indeed characteristic, subgroups with locally nilpotent or locally finite factors.

Theorem D. Let $G$ be a locally generalized radical group, whose subgroups are malonormal. If $G$ is non-periodic, then $G$ is Abelian.

\section{REFERENCES}

1. Baumslag, B. (1968). Generalized free product whose two-generator subgroups are free. J. London Math. Soc., 43, pp. 601-606.

2. Gorenstein, D. (1980). Finite groups of prime power order. New York: Chelsea Publ. Co.

3. Flavell, P. (2000). A note on Frobenius groups. J. Algebra, 228, pp. 367-378.

4. De la Harpe, P. \& Weber, C. (2014). Malnormal subgroups and Frobenius groups: basics and examples. Confluentes Math., 6, pp. 1, 65-76.

5. Kirichenko, V. V., Kurdachenko, L. A. \& Subbotin, I. Ya. (2011). Some related to pronormality subgroup families and the properties of a group. Algebra Discrete Math., 11, pp. 75-108.

6. Baer, R. (1933). Situation der Untergruppen und Struktur der Gruppe. S.-B. Heidelberg Akad., 2, pp. 12-17.

7. Olshanskii, A. Yu. (1981). An infinite group with subgroups of prime orders. Math. USSR-Izv., 16, pp. 279-289.

8. Chernikov, S. N. (1970). Infinite non-Abelian groups with normality condition for infinite non-abelian subgroups. Dokl. AN SSSR, 194, No. 6, pp. 1280-1283 (in Russian).

Received 21.08.2018

\section{Л.А. Курдаченко ${ }^{1}$, М.М. Семко ${ }^{2}$, І.Я. Субботін ${ }^{3}$}

${ }_{1}^{1}$ Дніпровський національний університет ім. Олеся Гончара

2 Університет державної фіскальної служби України, Ірпінь

${ }^{3}$ Національний університет, Лос-Анджелес, США

E-mail: 1kurdachenko@i.ua,dr.mykola.semko@gmail.com, isubboti@nu.edu

ПРО УЗАГАЛЬНЕННЯ МАЛНОРМАЛЬНИХ ПІДГРУП

Підгрупа $H$ групи $G$ називається малонормальною в $G$, якщо $H \cap H^{x}=\langle 1\rangle$ для кожного елемента $x$, що не належить до $N_{G}(H)$. Такі підгрупи є узагальненням малнормальних підгруп. Кожна малнормальна підгрупа є малонормальною і кожна самонормалізована малонормальна підгрупа є малнормальною. Кожна нормальна підгрупа також є малонормальною. Отримано опис скінченних та деяких нескінченних груп, кожна підгрупа яких є малонормальною.

Ключові слова: малнормальна підгрупа, малонормальна підгрупа, група Фробеніуса, узагальнена радикальна група. 
Л.А. Курдаченко ${ }^{1}$, Н.Н. Семко ${ }^{2}$, И.Я. Субботин ${ }^{3}$

1 Днепровский национальный университет им. Олеся Гончара

2 Университет государственной фискальной службы Украины, Ирпень

${ }^{3}$ Национальный университет, Лос-Анджелес, США

E-mail: 1kurdachenko@i.ua,dr.mykola.semko@gmail.com, isubboti@nu.edu

ОБ ОБОБЩЕНИИ МАЛНОРМАЛЬНЫХ ПОДГРУПП

Подгруппа $H$ группы $G$ называется малонормальной в $G$, если $H \cap H^{x}=\langle 1\rangle$ для каждого элемента $x$, который принадлежит к $N_{G}(H)$. Такие подгруппы являются обобщением малнормальных подгрупп. Каждая малнормальная подгруппа является малонормальной и каждая самонормализованная малонормальная подгруппа является малнормальной. Каждая нормальная подгруппа также является малонормальной. Получено описание конечных и некоторых бесконечных групп, каждая подгруппа которых будет малонормальной.

Ключевые слова: малнормальная подгруппа, малонормальная подгруппа, группа Фробениуса, обобщенная радикальная группа. 